\title{
Aplicabilidade do PRF- fibrina rica em plaquetas na Odontologia e seus benefícios
}

\author{
Applicability of PRF- platelet-rich fibrin in Dentistry and it's benefits \\ Aplicabilidad de PRF- fibrina rica en plaquetas em Odontología y sus beneficios
}

Recebido: 08/10/2021 | Revisado: 15/10/2021 | Aceito: 16/10/2021 | Publicado: 18/10/2021

\author{
Nathane Araujo de Carvalho \\ ORCID: https://orcid.org/0000-0003-3416-6183 \\ Faculdade Patos de Minas, Brasil \\ E-mail: nathanearaujo15@gmail.com \\ Carlos Eduardo Côrtes Morais \\ ORCID: https://orcid.org/0000-0002-8901-4294 \\ Faculdade Patos de Minas, Brasil \\ E-mail: carlos.morais.odonto@gmail.com \\ Fernando Nascimento \\ ORCID: https://orcid.org/0000-0003-3568-3887 \\ Faculdade Patos de Minas, Brasil \\ E-mail: fernando.nascimento@ faculdadepatosdeminas.edu.br \\ Lia Dietrich \\ ORCID: https://orcid.org/0000-0001-7887-8591 \\ Universidade Federal dos Vales do Jequitinhonha e Mucuri, Brasil \\ E-mail: dietrichlia.ld@gmail.com \\ Marcelo Dias Moreira de Assis Costa \\ ORCID: https://orcid.org/0000-0001-9148-3674 \\ Universidade Federal de Uberlândia, Brasil \\ E-mail: marcelodmac@yahoo.com.br
}

\begin{abstract}
Resumo
Proporcionar uma cicatrização rápida de tecidos moles e tecidos duros tornou o maior objetivo dos cirurgiões em geral, essa busca deu início aos estudos de aditivos cirúrgicos bioativos autólogos como: fibrina adesiva, concentrado plaquetário rico em plasma e em fibrina. A fibrina rica em plaquetas-PRF foi produzida na França sendo um concentrado plaquetário de segunda geração que devido as suas propriedades proporcionou resultados satisfatórios aplicados a odontologia permitindo uma excelente cicatrização e reparo de lesões cirúrgicas, auxiliando na regeneração de tecidos. É um biomaterial seguro $100 \%$ autólogo, de rápida aquisição, mais econômico, sem contraindicação, produto da centrifugação do sangue venoso natural do paciente. Hoje muitas pesquisas foram feitas relatando o uso do PRF como coagulo e membranas de PRF. No geral é aplicado em cirurgias orais para aumento ósseo, elevação do seio maxilar, em periodontia atuando na correção de defeitos intraósseos e recessão gengival, também pode ser usado para regeneração em ápice aberto, pulpotomias regenerativas e cirurgias periapicais. O presente trabalho trata-se de uma revisão de literatura qualitativa que tem como finalidade realizar um estudo planejando aprofundar o conhecimento sobre a aplicação do PRF- Fibrina Rica em Plaquetas. As buscas ocorreram por meio de realização de pesquisas seletivas de artigos, monografias e teses achados em bases de dados eletrônicas como: Pubmed, Scielo e Google Acadêmico com o objetivo descrever sobre os fatores de crescimento presentes no PRF, detalhar a aplicabilidade do PRF em procedimentos clínicos odontológicos e relatar os benefícios e vantagens do PRF sobre o PRP.
\end{abstract}

Palavras-chave: Fibrina rica em plaquetas; Plasma rico em plaquetas; Fatores de crescimento.

\begin{abstract}
Providing a quick healing of soft tissue and hard tissue became the greatest goal of surgeons in general, this search started the studies of autologous bioactive surgical additives such as: adhesive fibrin, platelet concentrate rich in plasma and fibrin. Platelet-rich fibrin-PRF was produced in France and is a second-generation platelet concentrate that, due to its properties, provided satisfactory results applied to dentistry, allowing for excellent healing and repair of surgical lesions, aiding in tissue regeneration. It is a $100 \%$ autologous safe biomaterial, quick to acquire, more economical, without contraindication, product of the centrifugation of the patient's natural venous blood. Today, much research has been done reporting the use of PRF as a clot and PRF membranes. It is generally applied in oral surgeries for bone augmentation, maxillary sinus elevation, in periodontics, acting in the correction of intraosseous defects and gingival recession, it can also be used for regeneration in open apex, regenerative pulpotomies and periapical surgeries. The present work is a qualitative literature review that aims to carry out a study planning to deepen the knowledge about the application of PRF-Fibrina Rica in platelets. The searches were carried out through selective research of articles, monographs and theses found in electronic databases such as: Pubmed, Scielo and Academic
\end{abstract}


Google with the objective of describing the growth factors present in the PRF, detailing the applicability of the PRF in procedures dental clinics and report the benefits and advantages of PRF over PRP.

Keywords: Platelet-rich fibrin; Platelet rich plasma; Growth factors.

\begin{abstract}
Resumen
Proporcionar una curación rápida de los tejidos blandos y duros se convirtió en el mayor objetivo de los cirujanos en general, esta búsqueda inició los estudios de aditivos quirúrgicos bioactivos autólogos como: fibrina adhesiva, concentrado de plaquetas rico en plasma y fibrina. La fibrina-PRF rica en plaquetas se produjo en Francia y es un concentrado de plaquetas de segunda generación que, por sus propiedades, proporcionó resultados satisfactorios aplicados a la odontología, permitiendo una excelente cicatrización y reparación de lesiones quirúrgicas, ayudando a la regeneración tisular. Es un biomaterial $100 \%$ autólogo seguro, de rápida adquisición, más económico, sin contraindicaciones, producto de la centrifugación de la sangre venosa natural del paciente. Hoy en día, se han realizado muchas investigaciones que informan sobre el uso de PRF como coágulo y membranas de PRF. Generalmente se aplica en cirugías bucales para aumento óseo, elevación de seno maxilar, en periodoncia, actuando en la corrección de defectos intraóseos y recesión gingival, también puede ser utilizado para regeneración en ápice abierto, pulpotomías regenerativas y cirugías periapicales. El presente trabajo es una revisión de la literatura cualitativa que tiene como objetivo realizar una planificación de estudios para profundizar en el conocimiento sobre la aplicación de PRF-Fibrina Rica en plaquetas. Las búsquedas se realizaron mediante la búsqueda selectiva de artículos, monografías y tesis encontradas en bases de datos electrónicas como: Pubmed, Scielo y Academic Google con el objetivo de describir los factores de crecimiento presentes en el PRF, detallando la aplicabilidad del PRF en los procedimientos de clínicas dentales. e informar los beneficios y ventajas de PRF sobre PRP.
\end{abstract}

Palabras clave: Fibrina rica en plaquetas; Plasma rico en plaquetas; Factores de crecimiento.

\title{
1. Introdução
}

Um grande objetivo dos cirurgiões da atualidade é proporcionar aos seus pacientes uma cicatrização mais rápida e efetiva tanto em tecidos moles quanto ósseos, sendo esse o marco que deu início aos estudos e pesquisas buscando aditivos cirúrgicos bioativos autólogos tais como o plasma rico em plaquetas (PRP) e fibrina rica em plaquetas (PRF) (Roveri,2018).

A fibrina rica em plaquetas (PRF) é um concentrado plaquetário elaborado na França, propondo sua prática na cirurgia oral e maxilofacial. É um produto de preparo destinado ao uso autólogo, permitindo um reparo mais rápido de áreas cirúrgicas. Classificado como um biomaterial de segunda geração dos agregados plaquetários, é conseguido após a coleta de sangue do próprio paciente e sua centrifugação única. Forma-se rapidamente, formando uma rede de fibrina rica em fatores de crescimento e citocinas. Sem do usado em tecidos moles e duros auxiliando no reparo dos tecidos (Choukroun, Adda, \& Schoeffler, 2001).

Um protocolo padrão para o preparo do concentrado fibrina rica em plaquetas e leucócitos (LPRF), uma nova denominação dada ao primeiro concentrado de segunda geração concebido, precisa ser seguido para obter a qualidade e quantidade satisfatória da matriz de fibrina, leucócitos, plaquetas e fatores de crescimento. A técnica consiste na coleta de uma porção de sangue do paciente em um tubo de vidro sem aditivos, imediatamente centrifugado a $700 \mathrm{~g}$ por 12 minutos. Ao longo do processo de centrifugação, quando o sangue entra em contato com a parede do tubo de vidro, as plaquetas são ativadas dando início a cascata de coagulação. Posterior a centrifugação, o produto consiste em três camadas distintas, sendo a camada superior plasma pobre em plaquetas (PPP) acelular, o coágulo de LPRF ao meio e as células vermelhas do sangue na porção inferior do tubo centrifugado. O coágulo de fibrina obtido após a centrifugação é removido do tubo e os glóbulos vermelhos aderidos são raspados e descartados. Posteriormente o LPRF é transformado na forma de membrana pela sua compressão, consequentemente eliminando os fluidos presentes no seu interior (Preeja \& Arun, 2014).

O LPRF obteve relevância na área odontológica, uma vez que consiste em um aglomerado plaquetário autólogo, econômico, sem contraindicações para seu uso e rico em plaquetas, leucócitos, citocinas, proteínas e fatores de crescimento. O LPRF é um biomaterial que pode ser aplicado em vários procedimentos odontológicos, associado ou não a outros biomateriais oferecendo assim resultados positivos e satisfatórios em relação ao reparo tanto de tecido moles, quanto a tecidos ósseos (Choukroun et al., 2001). 
Objetivo desse trabalho é descrever através de uma revisão de literaturas sobre os fatores de crescimento presentes nos agregados plaquetários, relatar as possíveis indicações do LPRF em procedimentos clínicos odontológicos e relatar os benefícios e vantagens do LPRF sobre o PRP.

\section{Metodologia}

$\mathrm{O}$ trabalho refere-se a uma revisão de literatura qualitativa que tem como finalidade realizar um estudo planejando aprofundar o conhecimento sobre a aplicação do PRF- Fibrina Rica em Plaquetas na prática odontológica, tendo em mente suas indicações e benefícios que melhoram significativamente a cicatrização e regeneração tecidual. O estudo foi elaborado através de buscas de dados que incluem um maior entendimento sobre o PRF. As buscas ocorreram por meio de realização de pesquisas seletivas de artigos, monografias e teses achados em bases de dados eletrônicas como: Pubmed, Scielo e Google Acadêmico. As palavras chaves que auxiliaram nas buscas foram: Fibrina Rica em Plaquetas. Plasma Rico em Plaquetas. Fatores de Crescimento.

\section{Revisão de Literatura}

\subsection{Fatores de Crescimento}

Historicamente, os agregados plaquetários de PRP e PRF foram usados inicialmente no tratamento e prevenção de hemorragias causadas por trombocitopenia severa. A aplicação de produtos provenientes do sangue com a finalidade de agilizar os processos de cicatrização se iniciou com o emprego de colas de fibrina, descritas inicialmente a mais de 45 anos (Borges, 2016).

Segundo Borges (2016), o objetivo da produção de agregados plaquetários é correlacionar as propriedades selantes da fibrina com os fatores de crescimento plaquetário, proporcionando assim um modelo ideal para a cicatrização de feridas e regeneração tecidual.

Segundo Dohan, Rasmusson e Albrektsson (2009), inúmeras técnicas são utilizadas para produção dos agregados plaquetários; porém, sua produção e aplicação são confusas, uma vez que cada método para a obtenção dos agregados plaquetários leva a aquisição de um produto com diferentes propriedades biológicas e usos distintos.

Conforme Vendramin, Franco, Nogueira, Pereira e Franco (2006), no mínimo sete fatores de crescimento diferenciados estão incluídos no processo reparador, liberados por plaquetas em função ativa desempenhando um papel relevante na fase inicial de cicatrização de feridas, referindo-se a dois deles fatores de crescimento transformadores (TGF) TGF $\beta 1$ e TGFß2. Possui também o fator de crescimento endotelial vascular, (VEGF). E por último, o fator de crescimento epitelial, (EGF).

O fator de crescimento derivado de plaquetas (PDGF), exclusivamente, é um fator quimiotático, atraindo os fibroblastos onde ocorrerá a agregação plaquetária e possibilita a síntese do colágeno e proteínas. Brandão (2005), afirma que o PDGF aparenta ser o primeiro fator de crescimento presente em uma ferida e dá início a reparação do tecido conjuntivo, como também do tecido ósseo. Suas ações especificas mais importantes incluem angiogênese, mitogênese e atividades de macrófagos (Sánchez, \& Sheridan 2003).

O TGF $\beta$, é um regulador de crescimento celular que atua na estimulação da matriz do osso, produz fibronectina e colágeno, atua também na biossíntese de osteonectina e induz a deposição da matriz óssea. Seu papel importante é quimioatratar e estimular os osteoblastos e a correção óssea na matriz de colágeno doente (Lemos, Rossi \& Píspico 2005; Marx 2004; Martínez et al 2002). 
Os fatores de crescimento semelhantes a insulina (IGFs) I e II estimulam a formação de osso induzindo a proliferação celular e a biossíntese do colágeno. Associado ao PDGF, os IGFs aumentam a taxa e a qualidade do reparo, aumentando também o processo de ossificação (Martínez et al 2002; Winkler, Pasleau, Boussif, \& Hodzic 2000).

O VEGF é produzido em grandes quantidades pelos leucócitos com um papel importante na angiogênese sendo fundamental para o processo de reparo tecidual. Os leucócitos por sua vez têm uma ação anti-inflamatória e regulação imune importante (Takamori, Teixeira, Menezes, Carias, \& Borojevic, 2018).

\subsection{Aplicações do PRF na odontologia}

Atualmente os concentrados sanguíneos têm sido amplamente aplicados nas áreas de cirurgia oral, cirurgia ortopédica, cirurgia plástica e dermatologia, como tratamentos para defeitos ósseos alveolares, lesões agudas de músculos, lesões de tendões e ligamentos, lesões articulares, osteoartrite, rejuvenescimento da pele, cicatrizes, redução dos sinais e sintomas da inflamação, queda de cabelo, reparo pós-cirúrgico e outros (Kawase, Mubarak, \& Mourão, 2020).

Atualmente muitas pesquisas foram feitas sobre os concentrados sanguíneos e inúmeros casos foram relatados mostrando o uso de suas membranas e coágulos. Em geral as pesquisas concentram-se na sua aplicação clínica como já foram descritas na preservação do alvéolo após extração, regeneração óssea após enucleação cística, elevação do assoalho do seio nasal e maxilar, preservação da crista alveolar e terapia regenerativa associada a implantes dentários, reparo de defeito intraósseo, reparo de defeito de furca e cirurgia plástica periodontal (M.Agrawala, \& Agrawala, 2014).

\subsubsection{Cirurgia Oral}

Estudos apresentam o PRF como um material de preenchimento em cirurgias de extração dentária, onde atuará de forma semelhante a um coágulo, produzindo uma matriz firme para sustentação da neovascularização e reparo tecidual acelerado. Isso pode ser usado para melhora do reparo de feridas em imunocomprometidos e pacientes diabéticos. Além disto, como PRF estimula a coagulação e pode ser utilizado como um adjuvante em pacientes em terapia anticoagulante (M.Agrawala, \& Agrawala, 2014).

O concentrado sanguíneo tem sido bastante aplicado em cirurgias de elevação de seio maxilar. Estudos indicam seu uso como único material de preenchimento durante a elevação do seio maxilar, outros estudos mostram o uso de PRF associado a material de enxerto ósseo em várias técnicas diretas e indiretas de elevação do seio maxilar como elevação do assoalho sinusal pela técnica de janela lateral ou elevação por meio de osteótomo. Alguns estudos também mostram o uso de PRF associado ao beta fosfato tricálcico (beta TCP) sem enxerto ósseo em manobras de elevação do seio e lesões periodontais crônicas (Gupta, Bains, Singh, Mathur, \& Bains, 2011).

O preenchimento de alvéolos com concentrados sanguíneos leva a resultados satisfatório quando as paredes ósseas estão intactas. Uma mistura de PRF com substitutos ósseos pode ser essencial em defeitos residuais onde uma ou mais paredes estão faltando ou danificadas, fornecendo uma reconstrução apropriada do volume ósseo. O PRF amplia a coesão entre os materiais de enxerto, já que a fibrina atua como cola fisiológica entre os tecidos. A coagulação natural do sangue leva à criação de uma matriz de fibrina que biologicamente facilita a chegada de células na ferida, facilitando a proliferação, migração celular, aposição de neomatriz e remodelação (M.Agrawala, \& Agrawala, 2014).

A fibrina rica em plaquetas pode ser aplicada como uma membrana para regeneração óssea guiada, na qual uma arquitetura tridimensional forte e elástica age como uma tela suturável que recobre e estabilizará o material enxertado, protegendo o biomaterial e a própria ferida, facilitando a aproximação dos bordos gengivais e, desse modo, beneficiando a sua reepitelização. (Del Corso, Toffler, \& Dohan Ehrenfest, 2010). 


\subsubsection{Periodontia}

Em periodontia, os concentrados sanguíneos têm sido usados para tratar recessão gengival, defeitos intraósseos e lesões periapicais, onde alguns relatos apresentam uma combinação do PRF, enxerto de hidroxiapatita e regeneração tecidual guiada (GTR). Mostram também a aplicação de coágulo e membrana de PRF associada com enxerto ósseo para tratar um dente com lesão endo-perio. (Shivashankar, Johns, Vidyanath, \& Sam, 2013)

O PRF estimula a proliferação de osteoblastos, células do ligamento periodontal e fatores de crescimento e suprimiu o crescimento das células epiteliais orais. Essas células de ações específicas podem ser benéficas para regeneração periodontal. Quando usado como uma membrana para a regeneração guiada como um material de enxerto cria um efeito de criação de espaço que facilita eventos celulares que são promissores para regeneração periodontal levando a processar a formação de tecidos mineralizados. Um estudo realizado para o tratamento de defeitos de furca grau II mandibulares com PRF, mostrou uma melhoria significativa para reduzir a profundidade da bolsa e também ganho no nível de inserção clínica e osso. (Preeja, \& Arun, 2014; Sharma, \& Pradeep, 2011)

O objetivo final do tratamento periodontal é a regeneração das estruturas periodontais perdidas, com a finalidade de restaurar a saúde, a função e a estética. Para determinar o sucesso clinico do tratamento periodontal regenerativo os principais resultados é a diminuição da profundidade de sondagem, ganho no nível de inserção clínica, diminuição da profundidade do defeito ósseo e preenchimento radiográfico do mesmo. Ao longo dos anos diversos tipos de biomaterias têm sido utilizados no tratamento de defeitos ósseos. Certos autores procuram estudar as propriedades biológicas do PRF, utilizando-o no tratamento de defeitos periodontais, onde o PRF é introduzido no defeito depois da completa remoção do tecido de granulação, posteriormente coberto com membranas do mesmo material. (Shah et.al., 2014)

O uso de PRF no tratamento de defeitos verticais em pacientes com periodontite revelou melhores resultados clínicos e um maior preenchimento do defeito comparado a um retalho de acesso sem utilização de biomaterias. (Sharma, \& Pradeep, 2011)

Chandradas, Ravindra, Rangaraj, Jain e Dasappa (2016) fizeram um estudo comparando o efeito da utilização separada do PRF, a utilização do PRF + xenoenxerto e o retalho de acesso na regeneração dos defeitos verticais em 36 pacientes. Observaram uma maior redução na profundidade de sondagem, um maior ganho de inserção e um maior preenchimento do defeito ósseo (avaliado radiograficamente) nos casos onde foi utilizado o PRF + xenoenxerto.

\subsubsection{Endodontia}

Estudos apontam que os concentrados sanguíneos conseguem ser utilizado como um material de apoio em um dente necrótico para regeneração pulpar e revitalização dentaria (Shivashankar, Johns, Vidyanath, \& Kumar, 2012). Além disso, casos demonstram que a associação de membrana de PRF como uma matriz e MTA em procedimentos de apicificação, comprova ser um caminho eficaz para criação de bloqueios artificiais de raiz e para incentivar uma cicatrização periapical mais rápida em casos de grandes lesões periapicais. A utilização do PRF em procedimentos regenerativos de pulpotomias também foram documentados onde a polpa coronária é removida a lesão pulpar é coberta por PRF e logo depois selagem com MTA e cimento de ionômero de vidro (Geeta, Galagali, Kulkarni, Suran, \& Noushin, 2013). O PRF é relacionado em preenchimento de falhas ósseas após cirurgias periapicais como ressecção apical de raiz (M.Agrawala, \& Agrawala, 2014).

O PRF pode servir com acréscimo ideal em revascularização de dentes permanentes imaturos com polpa necrótica, já que é rica em fatores de crescimento, intensificando a proliferação e diferenciação celular e funciona como uma matriz para crescimento do tecido (Shivashankar et.al., 2012). 


\subsubsection{Tratamento estético facial}

A fibrina rica em plaquetas é um biomaterial onde sua principal propriedade é a quimiotaxia, sendo capaz de conduzir em sua superfície as migrações de células epiteliais e leucócitos, do mesmo modo induz condições adequadas para a microvascularização (Takamori, Teixeira, Menezes, Carias, \& Borojevic, 2018; Wang, Yang, Zhang, \& Miron., 2019).

Alguns autores apresentam inúmeras utilizações do PRF em procedimentos estéticos faciais, pelo fato de atuar diretamente sobre o processo de cicatrização evitando em vários casos a formação de queloides obtendo um harmônico e satisfatório rejuvenescimento facial. Destacam que o PRF não proporciona toxicidade na pele, sendo capaz de potencializar a migração de fibroblastos quando comparados ao PRP. No contexto clinico, significa que durante a regeneração local as células ativadas serão recrutadas para os tecidos que apresentam defeitos após a aplicação (Karimi, \& Rockwell, 2019; Sclafani, 2010; Takamori et.al., 2018; Varela et.al., 2018;).

Quando se fala dos benefícios da fibrina rica em plaquetas na cosmética, Hassan, Quinlan e Ghanem (2020), apontam com precisão as funções e as vantagens do PRF. Um dos experimentos relatados foi a utilização injetável como preenchedor dérmico que acarretou na restauração do volume das cavidades lacrimais, atenuação das linhas finas e homogeneidade na irregularidade de pigmentação. Além disto, verificaram que durante o tratamento conforme o corpo metabolizava o material preenchedor, eram liberados fatores de crescimento responsáveis pelo deposito de colágeno.

\subsection{Vantagens do PRF em relação ao PRP}

Dohan et al. (2006) fala que a principal diferença entre o PRP e o PRF é que o PRP precisa de trombina bovina ou cloreto de cálcio, enquanto no PRF as concentrações de trombina que trabalham sobre o fibrinogênio autólogo são fisiológicas, não havendo a adição de agentes químicos externos.

Uma vantagem que o PRF tem sobre o PRP se dá pela na facilidade de preparação, simplicidade de aplicação, baixo custo e reduz consideravelmente a manipulação bioquímica do sangue já que usa aditivos, tal como os riscos relacionados ao uso de trombina de origem bovina. Devido ao fato do PRF possuir trombina fisiologicamente disponível resultando em uma lenta polimerização de fibrinogênio em fibrina, ocasionando em uma arquitetura fisiológica benéfica ao reparo de feridas (Preeja, \& Arun, 2014).

Outra vantagem que o PRF possui é uma estrutura flexível tridimensional tornando mais favorável o enredamento das citocinas e migração celular, já o PRP representa um condensado de fibrina deixando os polímeros mais densos levando a uma rede rígida. O PRF ainda apresenta o efeito de suporte no sistema imune e ajuda na hemostasia (Agrawala, \& Agrawala, 2014).

Quando se compara o PRP e PRF e seus efeitos alcançados pela liberação de fatores de crescimento necessários para os processos fisiológicos de cicatrização de feridas e reparo de tecidos observamos no geral uma maior liberação desses fatores nos coágulos produzidos a partir do PRF, e esses fatores liberados são observados por um período maior, de até 10 dias nesse concentrado (Hartshorne, \& Gluckman, 2016)

\section{Discussão}

O PRF foi apresentado como a segunda geração dos agregados plaquetários por Choukroun, Adda, Schoeffler e Vervelle, (2001), possui uma técnica de obtenção simples não havendo necessidade de um manuseio mais complexo, conferindo uma superioridade ao PRP.

A fibrina rica em plaquetas é capaz de ser utilizado na promoção de cicatrização de feridas, regeneração óssea, como estabilizador de enxerto, atuando no fechamento de feridas e na hemostasia. A polimerização lenta que a membrana de PRF apresenta concede uma arquitetura fisiologia especialmente favorável no processo de cicatrização e na migração das células. Independentemente das plaquetas e citocinas leucocitárias realizar um papel significativo na biologia do biomaterial, o apoio 
da matriz de fibrina certamente estabelece o componente determinante para o potencial terapêutico do PRF (Cardoso, \& Lopes, 2015; Naik, Karunakar, Jayadev, \& Marshal, 2013).

O sucesso para obter o PRF irá depender da velocidade de coleta e transferência do sangue para a centrifuga, pois, a amostra de sangue começa a coagular após o contato com o tubo de vidro levando a alguns minutos de centrifugação para juntar fibrinogênio na parte média e superior do tubo. Manuseio rápido é a maneira de conseguir uma membrana de PRF utilizável clinicamente e qualquer demora para coletar o sangue e começar a centrifugação poderá causar falha na técnica, ocasionando na polimerização da fibrina disseminada pelo tubo com a formação de um coágulo pequeno, sem resistência (Dohan et. al, 2006).

O processo de coagulação do PRF ocorre de forma natural e espontânea proporcionando a fácil obtenção do coagulo rico em fibrina envolvendo leucócitos, não havendo necessidade de mudança bioquímica do sangue devido ao uso de anticoagulantes, trombina ou cloreto de cálcio. Existe uma colaboração natural entre as plaquetas, fibrina e leucócitos para promover a cicatrização e regeneração tecidual. Os leucócitos apresentam uma importante ação anti-infecciosa, regulação imune e, também, fabrica altas quantidades do fator de crescimento de endotélio vascular (VEGF) que possui um papel importante na angiogênese, sendo fundamental no processo de regeneração tecidual (Ehrenfest, Rasmusson, \& Albrektsson, 2009; Ehrenfest, Sammartino, Shibli, Wang, Zou, \& Bernard, 2013).

Desde a primeira técnica de obtenção do PRF desenvolvida por Choukron outros protocolos passaram a ser desenvolvidos com o intuito de mudar a estrutura de fibrina, assim como das células que fazem parte da matriz obtida, com a proposta de melhoria da atuação do PRF nos processos de regeneração tecidual. Mudanças tem sido proposta, quanto a forca relativa e ao tempo de centrifugação, já que estes são elementos-chaves para mudar a estrutura de composição das matrizes de PRF (Choukroun, \& Ghanaati,2018; Ghanaati et al., 2014; El Bagdadi et al., 2019).

Observa-se que existem várias estruturas da matriz de fibrina, podendo ser obtidas em diferentes técnicas onde a velocidade tende a variar, bem como o tempo de centrifugação. A utilização da técnica de obtenção mais adequada deve levar em consideração a situação clínica de cada paciente (Alves, \& Granja, 2019).

\section{Conclusão}

Concluímos que um dos principais fatores que faz o PRF ser uma ótima aquisição na odontologia é o fato de possuir uma técnica simples, de fácil obtenção e por não ter contraindicação devido a centrifugação do sangue ser do próprio paciente o que consequentemente diminui os riscos de efeito colateral, diferente do PRP que necessariamente precisa de aditivo sanguíneo para realizar o processo de coagulação como a trombina bovina, aumentando o risco de rejeição do paciente. Além disso o fato do PRF ser rico em fatores de crescimento contribui para uma melhor regeneração e cicatrização tecidual. Entretanto existem várias técnicas para obter o PRF, o que torna difícil determinar qual técnica é mais eficaz, contudo, devemos levar em consideração as condições clinicas de cada paciente para determinar qual técnica é a mais eficiente.

\section{Referências}

Agrawal, M., \& Agrawal, V. (2014). Platelet rich fibrin and its applications in dentistry-A review article. National Journal of Medical and Dental Research, 2(3), 51.

Alves, R., \& Granja, M. D. C. (2019). Fibrina rica em plaquetas (PRF)-Aplicações em Periodontologia e Implantologia. Revista OMD, 40, $27-35$.

Anversa Pereira Borges, E. (2016). PRF: Aplicabilidade Clínica em Odontologia (Publication No. 53) [Master's thesis, Instituto Latino Americano de Pesquisa e Ensino Odontológico]. Trabalho de Conclusão de Curso (Pós-Graduação em Implantodontia)

Brandão, G. F. (2005). Estudo comparativo entre eficácia clínica de enxertos ósseos (autógenos, alógenos e aloplásticos) com e sem utilização de Pplasma Rrico em Pplaquetas. Odontologia. 
Cardoso, M. L., \& Lopes, S. M. (2015). Fibrina Rica Em Plaquetas E Leucócitos (L-Prf). Diminuindo A Morbidade Em Procedimentos De Reconstruções Teciduais Orais. Monografia. Universidade Federal Fluminense.

Chandradas, N. D., Ravindra, S., Rangaraju, V. M., Jain, S., \& Dasappa, S. (2016). Efficacy of platelet rich fibrin in the treatment of human intrabony defects with or without bone graft: A randomized controlled trial. Journal of International Society of Preventive \& Community Dentistry, 6(Suppl 2), S153.

Choukroun, J., Adda, F., Schoeffler, C., \& Vervelle, A. P. R. F. (2001). Une opportunité en paro-implantologie: le PRF. Implantodontie, $42(55)$, e62.

Choukroun, J., \& Ghanaati, S. (2018). Reduction of relative centrifugation force within injectable platelet-rich-fibrin (PRF) concentrates advances patients' own inflammatory cells, platelets and growth factors: the first introduction to the low speed centrifugation concept. European journal of trauma and emergency surgery, 44(1), 87-95.

Del Corso, M., Toffler, M., \& Dohan Ehrenfest, D. M. (2010). Use of an autologous leukocyte and platelet-rich fibrin (L-PRF) membrane in post-avulsion sites: an overview of Choukroun's PRF. J Implant Adv Clin Dent, 1(9), 27-35.

Dohan, D. M., Choukroun, J., Diss, A., Dohan, S. L., Dohan, A. J., Mouhyi, J., \& Gogly, B. (2006a). Platelet-rich fibrin (PRF): a second-generation platelet concentrate. Part I: technological concepts and evolution. Oral surgery, oral medicine, oral pathology, oral radiology, and endodontics, 101(3), e37-e44. https://doi.org/10.1016/j.tripleo.2005.07.008

Dohan, D. M., Choukroun, J., Diss, A., Dohan, S. L., Dohan, A. J., Mouhyi, J., \& Gogly, B. (2006b). Platelet-rich fibrin (PRF): a second-generation platelet concentrate. Part II: platelet-related biologic features. Oral surgery, oral medicine, oral pathology, oral radiology, and endodontics, 101(3), e45-e50. https://doi.org/10.1016/j.tripleo.2005.07.009

Dohan, D. M., Choukroun, J., Diss, A., Dohan, S. L., Dohan, A. J., Mouhyi, J., \& Gogly, B. (2006c). Platelet-rich fibrin (PRF): a second-generation platelet concentrate. Part III: leucocyte activation: a new feature for platelet concentrates? Oral surgery, oral medicine, oral pathology, oral radiology, and endodontics, 101(3), e51-e55. https://doi.org/10.1016/j.tripleo.2005.07.010

Ehrenfest, D. M. D., Rasmusson, L., \& Albrektsson, T. (2009). Classification of platelet concentrates: from pure platelet-rich plasma (P-PRP) to leucocyte-and platelet-rich fibrin (L-PRF). Trends in biotechnology, 27(3), 158-167.

Ehrenfest, DD, Sammartino, G., Shibli, JA, Wang, HL, Zou, DR, \& Bernard, JP (2013). Diretrizes para publicação de artigos relacionados a concentrados de plaquetas (Plasma Rico em Plaquetas-PRP ou Fibrina Rica em Plaquetas-PRF): a classificação internacional da POSEIDO. Poseido J, 1, 17-28.

El Bagdadi, K., Kubesch, A., Yu, X., Al-Maawi, S., Orlowska, A., Dias, A., \& Ghanaati, S. (2019). Reduction of relative centrifugal forces increases growth factor release within solid platelet-rich-fibrin (PRF)-based matrices: a proof of concept of LSCC (low speed centrifugation concept). European Journal of Trauma and Emergency Surgery, 45(3), 467-479.

Geeta, I. B., Galagali, G., Kulkarni, S., Suran, P., \& Noushin, F. (2013). A natural meliorate: revolutionary tissue engineering in endodontics. Journal of clinical and diagnostic research: JCDR, 7(11), 2644.

Ghanaati, S., Booms, P., Orlowska, A., Kubesch, A., Lorenz, J., Rutkowski, J., \& Choukroun, J. (2014). Advanced platelet-rich fibrin: a new concept for cellbased tissue engineering by means of inflammatory cells. Journal of Oral Implantology, 40(6), 679-689.

Gupta, V., Bains, V. K., Singh, G. P., Mathur, A., \& Bains, R. (2011). Regenerative potential of platelet rich fibrin in dentistry: Literature review. Asian J Oral Health Allied Sci, 1, 23-8.

Hassan, H., Quinlan, D. J., \& Ghanem, A. (2020). Injectable platelet-rich fibrin for facial rejuvenation: A prospective, single-center study. Journal of Cosmetic Dermatology, 19(12), 3213-3221.

Hartshorne, J., \& Gluckman, H. (2016). A comprehensive clinical review of Platelet Rich Fibrin (PRF) and its role in promoting tissue healing and regeneration in dentistry. Int. Dentistry Afr. Ed, 6(5), 14-24.

Karimi, K. \& Rockwell, H. (2019). Os benefícios da fibrina rica em plaquetas. Clínicas de Cirurgia Plástica Facial, 27 (3), 331-340.

LEMOS, J., ROSSI JUNIOR, R., \& PÍSPICO, R. (2005). Utilização de plasma rico em plaquetas em enxertos ósseos-proposta de um protocolo de obtenção simplificado. 2002. Capturado em, 12.

Lins, V. F., Brandão, D. G., \& Rocha, S. M. W. (2021). A utilização da fibrina rica em plaquetas em procedimentos estéticos orofaciais: uma revisão integrativa. Research, Society and Development, 10(3), e27910313477-e27910313477.

Martínez-González, J. M., Cano-Sánchez, J., Gonzalo-Lafuente, J. C., Campo-Trapero, J., Esparza-Gómez, G. C., \& Seoane Lestón, J. M. (2002). ¿ Existen riesgos al utilizar los concentrados de plasma rico en plaquetas (PRP) de uso ambulatorio. Medicina Oral, 7(5), 375-90.

Marx, R. E. (2004). Platelet-rich plasma: evidence to support its use. Journal of oral and maxillofacial surgery, 62(4), 489-496.

Mourão, C. F. D. A. B., Valiense, H., Melo, E. R., Mourão, N. B. M. F., \& Maia, M. D. C. (2015). Obtention of injectable platelets rich-fibrin (i-PRF) and its polymerization with bone graft. Revista do Colégio Brasileiro de Cirurgiões, 42, 421-423.

Naik, B., Karunakar, P., Jayadev, M., \& Marshal, V. R. (2013). Role of Platelet rich fibrin in wound healing: A critical review. Journal of conservative dentistry: JCD, 16(4), 284.

Preeja, C., \& Arun, S. (2014). Platelet-rich fibrin: Its role in periodontal regeneration. The Saudi Journal for Dental Research, 5(2), 117-122.

Roveri, P. R. (2018). Obtenção de fibrina leocoplaquetaria na odontologia PRF e IPRF: revisão literária [Master's thesis, Faculdade Sete Lagoas]. Especialização em estetica orofacial. https://faculdadefacsete.edu.br/monografia/items/show/260. 
Research, Society and Development, v. 10, n. 13, e466101321570, 2021

(CC BY 4.0) | ISSN 2525-3409 | DOI: http://dx.doi.org/10.33448/rsd-v10i13.21570

Sánchez, A. R., Sheridan, P. J., \& Kupp, L. I. (2003). Is platelet-rich plasma the perfect enhancement factor? A current review. International Journal of Oral \& Maxillofacial Implants, 18(1).

Sclafani, A. P. (2010). Platelet-rich fibrin matrix for improvement of deep nasolabial folds. Journal of cosmetic dermatology, 9(1), 66-71.

Shah, M., Deshpande, N., Bharwani, A., Nadig, P., Doshi, V., \& Dave, D. (2014). Effectiveness of autologous platelet-rich fibrin in the treatment of intra-bony defects: A systematic review and meta-analysis. Journal of Indian Society of Periodontology, 18(6), 698.

Shah, R., Thomas, R., \& Mehta, D. S. (2017). An Update on the Protocols and Biologic Actions of Platelet Rich Fibrin in Dentistry. The European journal of prosthodontics and restorative dentistry, 25(2), 64-72.

Sharma, A., \& Pradeep, A. R. (2011). Autologous platelet-rich fibrin in the treatment of mandibular degree II furcation defects: A randomized clinical trial. Journal of periodontology, 82(10), 1396-1403.

Shivashankar, V. Y., Johns, D. A., Vidyanath, S., \& Kumar, M. R. (2012). Platelet rich fibrin in the revitalization of tooth with necrotic pulp and open apex. Journal of conservative dentistry: JCD, 15(4), 395.

Shivashankar, V. Y., Johns, D. A., Vidyanath, S., \& Sam, G. (2013). Combination of platelet rich fibrin, hydroxyapatite and PRF membrane in the management of large inflammatory periapical lesion. Journal of conservative dentistry: JCD, 16(3), 261.

Takamori, E. R., Teixeira, M. V. T., Menezes, K., Carias, R. B. V., \& Borojevic, R. (2018). Fibrina rica em plaquetas: preparo, definição da qualidade, uso clínico. Vigilância Sanitária em Debate: Sociedade, Ciência \& Tecnologia, 6(1), 118-124.

Varela, H. A., Souza, J. C., Nascimento, R. M., Araújo, R. F., Vasconcelos, R. C., Cavalcante, R. S., \& Araújo, A. A. (2019). Injectable platelet rich fibrin: cell content, morphological, and protein characterization. Clinical oral investigations, 23(3), 1309-1318.

Vendramin, F. S., Franco, D., Nogueira, C. M., Pereira, M. S., \& Franco, T. R. (2006). Plasma rico em plaquetas e fatores de crescimento: técnica de preparo e utilização em cirurgia plástica. Revista do Colégio Brasileiro de Cirurgiões, 33, 24-28.

Wang, X., Yang, Y., Zhang, Y., \& Miron, R. J (2019). A fibrina rica em plaquetas no fluido estimula uma maior migração, proliferação e síntese de colágeno de fibroblastos cutâneos dérmicos quando comparada ao plasma rico em plaquetas. Journal of cosmético dermatology, 18 (6), 2004-2010.

Winkler, R., Pasleau, F., Boussif, N., \& Hodzic, D. (2000). Le système IGF: synthèse et données récentes [The IGF system: summary and recent data]. Revue medicale de Liege, 55(7), 725-739. 